Article title: Lecturers' Experiences of the Blurring of Time and Space during Covid-19 in a South African ODeL University

Authors: Katharine Naidu[1], Mpho-Entle Puleng Modise [2]

Affiliations: University of South Africa[1]

Orcid ids: 0000-0002-5932-3520[1], 0000-0002-2817-6329[2]

Contact e-mail: naiduk1@unisa.ac.za

License information: This work has been published open access under Creative Commons Attribution License http://creativecommons.org/licenses/by/4.0/, which permits unrestricted use, distribution, and reproduction in any medium, provided the original work is properly cited. Conditions, terms of use and publishing policy can be found at https://www.scienceopen.com/.

Preprint statement: This article is a preprint and has not been peer-reviewed, under consideration and submitted to UnisaRxiv for open peer review.

Funder: None

DOI: 10.25159/UnisaRxiv/000014.v1

Preprint first posted online: 28 April 2021

Keywords: Covid-19, blurring boundaries, boundary theory, working from home, open and distance learning, ODL, e-learning, higher education 


\section{Lecturers' Experiences of the Blurring of Time and Space during Covid-19 in a South African ODeL University}

\author{
Katharine Naidu \\ https://orcid.org/0000-0002-5932-3520 \\ University of South Africa \\ naiduk1@unisa.ac.za
}

\author{
Mpho-Entle Puleng Modise \\ https://orcid.org/0000-0002-2817-6329 \\ University of South Africa \\ modismp@unisa.ac.za
}

\section{Abstract}

Education has been greatly impacted by the current Covid-19 pandemic. With countries worldwide experiencing unprecedented extended lockdowns, higher education providers have sought innovative technological ways of effectively delivering tuition and support to diverse students. This has, however, also increased the blurring of the work-home boundaries. This paper reports on the way in which Covid-19 facilitated the blurring of the work-home boundaries of academics in the College of Education at the University of South Africa, a distance education institution. Semi-structured interviews were used to collect data from 15 lecturers via Microsoft Teams. The results showed that, owing to a lack of workspace at their homes, many academics were forced to work beyond normal office hours. Inexplicit expectations from the employer exacerbated the blurring of work-home interfaces for many academics. The results of this study can be used for future research to seek ways in which the management of the University of South Africa or employers of other higher education institutions can help to reduce the blurring of work-home boundaries.

Keywords: Covid-19, blurring boundaries, boundary theory, working from home, open and distance learning (ODL), e-learning, higher education

\section{Introduction and Background}

The Covid-19 pandemic brought extraordinary changes and unimaginable disruptions to the education landscape, forcing educators to shift to an online mode of teaching overnight (Dhawan 2020). However, technology provided a workable transfer of teaching and learning activities to online spaces and online learning became the only solution to ensure continuity of education, life and work.

Information and communication technology (ICT) has often been blamed and praised for the many changes taking place in higher education, including the blurring of home and work boundaries. With the rise of ICTs, the work-home interface has been drastically altered. ICT has enabled work to be done at any time and in any location, 
thereby blending domains and removing boundaries between interfaces (Field and Chan 2018).

However, the Covid-19 pandemic and the subsequent lockdowns took work-home boundary blurring to unprecedented levels. It cannot be denied that the pandemic affected all aspects of life and work (Manzanedo and Manning 2020). All nations of the world (Ogundokun et al. 2020) were greatly impacted. The Covid-19 pandemic demanded that higher education institutions (HEIs) continue providing educational services to students by migrating to digital environments (Deslandes and Coutinho 2020; Gurukkal 2020).

Educational institutions in South Africa and across the world had to continue with teaching and learning activities by using various educational technologies. This created high levels of unexpected blurring of boundaries between work and home. As schools and childcare facilities were closed, academics with young children that required childcare and those with children at school, had to take care of their children, while simultaneously performing the duties and responsibilities of their employers. The blurring of the lecturers' home and work boundaries, specifically time and space, brought by the ubiquity of technology was inevitable.

The University of South Africa (Unisa) is an open and distance learning (ODL) institution that has a space-time concept of its own because the learners and lecturers are separated by physical distance (Moore 2013). In distance learning, education can be delivered synchronously and asynchronously (Brady and Pradhan 2020). However, the Covid-19 conditions became a problem because of the shock and unpreparedness they had brought about. The assumption is that an ODL institution should have been better prepared for this kind of disruption, however, this was not the case with Unisa which had only officially implemented e-learning in 2013 (Baijnath 2014). The Covid-19 pandemic is a huge challenge to education systems (Daniel 2020) and many institutions were clearly not prepared to teach and support remotely. Hodges et al. $(2020,1)$ explain that "well-planned online learning experiences are meaningfully different from courses offered online in response to a crisis or disaster".

This study sought to investigate the academics' experiences of the challenges posed by Covid-19, specifically the blurring of work-home boundaries. The research question that guided this article therefore was: How do academics in an ODL institution experience the blurring of work-home boundaries during the Covid-19 pandemic?

In this paper, work-home and work-family are used interchangeably. Work and office are also used interchangeably, and refer specifically to paid work, whereas home and non-work boundaries refer to the spaces outside the paid-work environments. 


\section{Literature Review}

Although the emergence of the Covid-19 pandemic accelerated the blurring of the work-home interface, this is not a new phenomenon. Studies show that technology has been the greatest catalyst of work-home interference (WHI) (Derks et al. 2015; Köffer et al. 2015). Studies show that work-life interface is becoming increasingly boundaryless, especially for technology-enabled workers such as academics (Field and Chan 2018).

The ubiquity of technology (Brown 2016) and the internet has become the panacea of everyday life's challenges, especially in education where teaching and learning could take place anytime and anywhere without boundaries. Derks et al. (2015) argue that the blurring of boundaries between work-home domains in modern society has been facilitated by ICTs and has increased non-standard work schedules (Derks and Bakker 2014).

The industrial revolution, which was fuelled by new technological developments, was also responsible for the temporal and spatial split between "work" and "family" (Craig 2020). Work-home interference refers to a "process of negative interaction between the work and the home domain" (Van Hooff et al. 2006, 145). This means that when the incumbents cannot manage and balance their WHIs, they will have negative perceptions and experiences that can bring some level of discomfort. Often the relationships within family settings are first to be adversely affected. Tabane (2020) argues that mental health can be adversely impacted as relationships are affected by challenged boundaries of time and space.

The challenge with work-home boundaries is that the demands in one domain if not well managed can deplete resources and impede accomplishments in the other (Ten Brummelhuis and Bakker 2012). Kinman (2016) indicated that for several reasons, knowledge workers, such as academics may have difficulties achieving an effective work-home balance. Kreiner, Hollensbe and Sheep (2009) investigated the way in which people manage boundaries to negotiate the demands between work and home life and found differences between the work-home conflict and "boundary violations", which they define as "behaviors, events, or episodes that either breach or neglect the desired work-home boundary" (704), meaning that a boundary is not treated in the way an individual prefers.

Stadtlander et al. (2017) stress the importance of employers understanding the needs of virtual workers and helping employees to set up a controlled and secure work environment while working from home. Stadtlander et al. $(2017,45)$ found that most of the participants in their study "consciously separated their home and workplace through either utilizing a separate room/area or maintaining a work schedule that separated work and home through the management of their time". Although some academics may have a main workstation in their homes, such as an office or a corner used exclusively for office work, work in other locations on digital devices around their home may still be 
done as a change of venue. The digital devices and use of social media by organisations, among other things, seem to have removed boundaries in terms of the time an employee may respond to the official work communication and/or demands. The Covid-19 situation brough new dimensions to work-home boundaries as not all academics have equal resources at home in terms of time and space to effectively manage the workhome conflicts. As mentioned earlier, the schools and early childhood education centres also closed because of the pandemic, therefore many households had to take over the childcare duties while expected to simultaneously perform work duties such research, teaching and learning and effectively supporting students.

\section{Theoretical Framework}

Negotiating and maintaining boundaries between work and home have been the concern of research in various disciplines for centuries (Kylin 2007), and thus it is not a new phenomenon. Politics, changing culture and socio-economic issues have ushered in the bridge between these boundaries, however, it was technology that accelerated the blending and blurring of the work and non-work boundaries. These subsequently gave birth to the boundary theory, which focuses on explaining everyday transitions such as work and home. And then Covid-19 pushed the blending and blurring of boundaries further. The unique situation with Covid-19 is that it affected the world and gave no one an option but to take paid work to their homes. The term "boundary" has been used in diverse contexts to refer to the "physical, temporal, emotional, cognitive and or relational limits that define entities as separate from one another" (Ashforth, Kreiner, and Fugate 2000, 474).

The boundary theory is a useful lens for understanding the interface between work and home or work-home relations and/or the interface between individual and organisational identity (Kreiner, Hollensbe, and Sheep 2009). Ashforth, Kreiner, and Fugate $(2000,474)$ described the boundary theory as a process whereby "individuals create and maintain boundaries as a means of simplifying and ordering the environment". These boundaries exist to secure different domains of life. Domains are described by Clark $(2000,753)$ as "worlds that people have associated with different rules, thought patterns and behaviour". Overlap between the domains occurs through integration (mixing of work and home domains) and segmentation (separating of work and home domains) mechanisms (Ashforth, Kreiner, and Fugate 2000; Nippert-Eng 1996). These mechanisms are some of the strategies that individuals use to simplify and order the boundaries to cope with the demands of different boundaries and to deal with work or family conflicts. Adults spend most of their working life striving for a workhome balance; however, the magnitude of Covid-19 disturbed and disrupted the traditional work-home balance as it was known.

When the boundaries are socially shared, Kreiner, Hollensbe and Sheep $(2009,706)$ warn that "they can become institutionalized to the point that they are very difficult to change or erase". Clark (2000) also warns that work and home cultures tend to create 
expectations about rules, attitudes, and behaviours that are often different from one another, thus creating conflicts. The concepts of segmentation and integration (Ashforth, Kreiner, and Fugate 2000; Nippert-Eng 1996) in boundary theory comes with varying degrees and can only exist when there is low flexibility and low permeability. Integration is characterised by high flexibility and high permeability, however, there are costs and benefits associated with segmenting one's roles versus integrating one's roles (Ashforth, Kreiner, and Fugate 2000, 473).

Kreiner, Hollensbe and Sheep (2009) identified other work-home boundary work tactics that are employed by academics to decrease work-home boundary incongruence, boundary violations and work-home conflicts. These tactics include behavioural tactics, temporal tactics, physical tactics and communication tactics. For example, Kreiner, Hollensbe and Sheep $(2009,717)$ identified behavioural tactics to include the tactic of "allowing differential permeability", which means an academic chooses which "specific aspects of work-home life will or will not be permeable" whereas with the physical tactics, an academic may manipulate physical space to manage the needs of both boundaries.

All these activities require constant planning and watching over the boundaries, which may in turn cause psychological detachment from work during off-job time. Psychological detachment, a "sense of being away from the work situation" was introduced by Etzion, Eden and Lapidot $(1998,579)$ to explain the importance for improving well-being during intervals and the need for individuals to mentally "switch off" from work-related thoughts and activities to recover from stress during non-work time (Park, Fritz, and Jex 2011). Covid-19 made it difficult for segmentation to occur in the homes of many academics. Integration and the overlapping of roles became the new normal during Covid-19 lockdowns. The context of Covid-19 nurtured and forced the flexibility and permeability of boundaries making it difficult for academics to maintain strong boundaries between work and home.

\section{Methodology}

A case study design compatible with qualitative research methods was used in this study. Case studies are important where the researcher has access to the participants in their real-life contexts. Investigating academics' experiences of the blurring of workhome boundaries during Covid-19 at one of Africa's large-scale ODL institutions (Tait 2013) with more than a hundred years of distance education (DE) provision allowed us to "retain the holistic and meaningful characteristics of real-life events" (Yin 2009, 4). ODL institutions operate within domains separated by time and space between lecturers and students, and it was important to understand the way in which an institution that has been providing DE for more than a hundred years experienced the sudden changes brought on by Covid-19. 


\section{Sampling}

Purposive sampling was used to select 15 lecturers (10 females and 5 males) from the College of Education at Unisa. Lecturers who met the practical criteria, such as the willingness to participate and their availability and accessibility (Suen, Huan, and Lee 2014), were selected. The College has a large population of lecturers who all experienced Covid-19 and work-related challenges. Not everyone was, however, available and willing to participate in our study; hence purposive sampling was used. This criterion was also used to manage the project better, given our limited time for the project (Etikan, Musa, and Alkassim 2016).

\section{Data Collection and Analysis}

Once identified, the participants were contacted via email and invited to participate. Owing to the Covid-19 restrictions, interviews were conducted and recorded online via Microsoft Teams and then sent for professional transcription. Semi-structured interviews were used because of the flexibility and ability to capture the participants' views and opinions (Iyamu 2018). The researchers used various functions and tools, among which were comments in Microsoft Word, and collaborative manual coding (Saldaña 2021) to immerse themselves in the data. Saldaña $(2021,44)$ explains that manual coding depends on many factors and in our case, it was the small size of the project and the flexibility of collaborating through the Microsoft Word program that encouraged our use of manual coding. Intercoder reliability was achieved through constant member checking (Hamilton 2020) and meetings. Thematic analysis (Braun and Clarke 2012; Lorelli et al. 2017) was used and the emerging themes of the blurring of time and space are discussed in the following sections.

\section{Ethical Considerations}

Ethical clearance to conduct this research was granted by the Ethics Committee of the College of Education. The detailed information on the scope of the study and the participants' rights was clearly communicated to the participants. They were also reassured of their anonymity and privacy. The interviews were conducted once the participants consented. The interviews were conducted online with the participants in the comfort of their own living spaces, which further ensured that they were not exposed to any harm. All ethical considerations were observed and maintained throughout the study.

\section{Findings}

The findings are presented in this section under the themes of the blurring of time, and the blurring of space. Most participants in this study had been teaching at Unisa for more than three years. Although they are mostly using the university's learning management system for teaching, some also use other social media tools to 
communicate and support their students. Most of the participants in this study were females, some with young children.

The objective of this study was to establish the way in which the blurring of work-home boundaries during Covid-19 had an impact on academics in an ODL and higher education institution. The blurring of time and space boundaries presented major challenges for most lecturers and their families. However, it emerged that most Unisa academics creatively negotiated their time and space within their work-home boundaries, while others found it difficult to smoothly transition to the new normal.

\section{Theme 1: Blurring of Time}

The flexibility of working from home blurred the boundaries of time as academics were no longer restricted to the standard office hours and this encouraged some academics to work according to non-standard work schedules - early in the mornings, late at night and over weekends (Derks and Bakker 2014).

Although it was never explicitly communicated to academics that they were expected to work after official hours, emails and text messages after hours prompted them to respond. This study found that academics felt a subtle expectation that they should work outside their official work hours and days, as revealed by one of the participants:

Messages would pop up at 7 o'clock in the evening and urgently require you to respond and you felt an urge to respond.

Another participant shared her experience of working outside the standard working hours:

... because sometimes some systems do not work well during the day, so I prefer to work late in the evening or very early in the morning around $2 \mathrm{am}$, on the jRouter or myUnisa or whatever.

One of the factors creating after-hours availability expectations (Mellner 2016) is believed to be resources such as a smartphones and data that the employer provided to workers. Derks and Bakker (2014) reported that receiving technical tools of support from their employers gave the respondents the impression that the employer had strong expectations of employees to be available for work after office hours. For example, during the Covid-19 lockdown, Unisa made allowances for data through partnerships with local mobile networks for academics to continue working from home. Interestingly, more night-owl data was provided than anytime data, this implied an expectation by the employer that the data be used by the academics at night. This further contributed to the blurring of time and space of academics (work-home responsibilities). 
Another finding was that the blurring of time was caused by the students' needs for instantaneous feedback and support during Covid-19. Some participants indicated that almost every email they received from the institution and from students had an urgent tag to it, prompting them to respond. The participants reported to have received emails and phone calls from students after office hours. One of the participants indicated that she transferred her office telephone line to her cellphone so that she could continue to effectively support her students during the lockdown:

As an ODL institution, I don't think the support given to student changed much because we never really had the students physically on campus ... that did not change, because the e-mails would still come and the other thing is that I actually transferred my office line to my cell phone, so even when they [students] called the office line, I could still assist them.

However, the students communicated with academics at all times also with the expectation that the academics respond to their requests immediately, even outside official working hours during Covid-19. One participant pointed out the following:

My students called me at night or at times at 5am. I realised that this was out of frustration as they were also working from home and wanted immediate help.

Working from home meant that both academics and administrative staff had to juggle roles such as spousal, parental and many other roles in family spaces invaded by work (Tabane 2020). This created some challenges, among which were constant disruptions, for example, children asking for help with school activities or just needing their parents' attention, spouses needing attention and/or neighbours mowing their lawns or doing work in their houses. This created a conflict of roles and a need to balance and prioritise work versus home responsibilities, resulting in some academics opting to do their work at night, when it was quieter and more peaceful. Although the time to spend with children was appreciated, it often competed with work duties. One participant pointed out the following: "we under-estimate the time [and attention] it takes to take care of children and [to] do domestic chores."

The "new normal" included online meetings and activities via Microsoft Teams that encroached on family time and space, further putting strain on the home arrangements. Most participants indicated the challenge of choosing which meeting or online workshop to attend, as they all seemed urgent and important, thereby increasing their stress levels.

Besides the challenges, academics mentioned some benefits of working from home, including increased productivity owing to the time saved by not travelling to and from work. One participant remarked:

We used to travel one hour from where I stayed to Unisa and leaving home at half past five to avoid traffic, but now we are not travelling ... and then I have more hours ... I 
have gained a lot because I have done a lot of work during this period. I have actually accomplished many things during this period.

Some participants appreciated the time saved on travelling and preferred the quiet, undisturbed time in their homes as this increased their productivity. The blurring of time cannot happen outside the boundaries of space; the next section discusses the way in which the blurring of work and home spaces affected the academics in these spaces.

\section{Theme 2: Blurring of Space}

When South Africa went into lockdown and universities closed, teaching and learning had to continue. Academics moved from their offices to their homes. For many academics this was a challenge as it was not easy to find suitable spaces in their homes to work from as many homes do not have designated study rooms or libraries. As a result, living rooms, bedrooms, guest rooms and garages became offices and lecture rooms; at times some academics reported that they had to negotiate the use of their kitchen tables with cooking space (Tabane 2020). One participant pointed out that:

The major shift was adapting my home to be suitable for work. I had to change my lifestyle at home so that I could accommodate my new work schedule.

Although Covid-19 enforced some creativity (Zawacki-Richter 2021) with resources, such as time and space, it also brought many challenges for everyone. Working from home meant that whatever space was available was shared with everyone in the family. Shared spaces thus negatively affected relationships. This also induced the blurring of roles and responsibilities (Ruppanner and Huffman 2014), putting further strain on the family as academics experienced greater conflict between work and family roles. Most academics in this study were females with children and some expressed the frustrations of role blurring created by the blurring of boundaries due to shared spaces or a lack of space in their homes. This resulted in many academics being forced to work until late in the evenings, often in their bedrooms, which is a place meant for rest.

Interestingly, not only female academics were challenged by the responsibility of taking care of children. One of the male participants in this study explained that his partner, an "essential worker", had to continue working outside their home while he had to babysit and take over home schooling responsibilities.

\section{Discussion}

The general practice in the world changed overnight in response to the Covid-19 pandemic (Khan et al. 2020) and most people found themselves negotiating and rearranging their spaces. Like many HEIs in Africa and other developing countries, Unisa officially implemented e- learning in 2013; however, to allow a smooth transition, they were still running some systems in a blended mode (Baijnath 2014). The sudden shift induced by Covid- 19 from the blended to a fully online approach came with some 
challenges. One of the challenges was related to examinations. Previously, students at Unisa wrote their examinations at a venue but with Covid-19 regulations all examinations had to be moved online immediately. This resulted in added stress for both students and academics as neither group was prepared for the challenges that an online examination would bring. For students, their anxiety was about issues of downloading their question paper and uploading their answer sheet. This anxiety was fuelled by the lack of stable connectivity and access to data. For academics, their anxiety included a lack of preparation and training by university management for the online examination implementation. Students and academics alike did not have the necessary technological skills to transition from a blended mode of teaching and learning to a fully online mode of delivery.

Institutions, academics and students were faced with new Covid-19 induced challenges that required careful thought and planning to achieve educational goals. Owing to the many changes with systems, planning and decisions that the university had to continuously make and communicate to academics and students, there seemed to be a communication and information overload, coupled by unmanaged, uncommunicated and unclear expectations from all stakeholders. Academics felt pressurised to work outside their standard work schedules for various reasons, for example, the data that was provided for night use, and students who demanded instantaneous feedback and help. Many participants struggled to simplify and order their work-home environments, as suggested by Ashforth, Kreiner, and Fugate's (2000) boundary theory. The magnitude and scale of Covid-19 disrupted the sought-after traditional work-home balance that many of us spend most of our lives striving for.

The appeal of the boundary theory is the idea of flexibility and ability of an individual to decide how much integration they can allow between work and non-work boundaries. However, the Covid-19 pandemic did not give much choice or options to most people. Working from home meant that the two worlds of home and office were merged into one, hence the blending and blurring of these boundaries. For example, the temporal boundary which may mean the end of a workday or a shift, allowing individuals to apply "psychological boundaries", with "rules dictating appropriate thinking patterns, behaviour patterns and emotions for domain" (Clark 2000, 756) was not possible during the Covid-19 lockdown. It was almost impossible for many lecturers to exercise their power between boundaries. This created a few discords in an individual's life and unsettled many family settings. It became difficult to use the segregation strategy during lockdown, and work-home integration happened almost automatically. Although many tried to demarcate spaces and times for work and for home activities, it was difficult for others and impossible for some, especially those with families and others with small houses.

Technology has been at the centre of the blurring of boundaries between work and home. The technology that enabled many institutions to continue teaching, communicating, connecting and supporting their students during the Covid-19 
lockdown ironically also accelerated the blurring of boundaries. Härmä (as cited in Derks and Bakker 2014, 411) found that technological advances increased non-standard work schedules. For example, mobile phones are designed to be carried on people's bodies for personal needs and work. The new normal meant that emails flooded inboxes at any time (blurring of time) irrespective of where the lecturers were (space blurring) and this that meant emails could be attended to anywhere and anytime. WhatsApp groups were also formed by some departments or teams to continue with business, for ease of access, quick update on matters, etc., and this meant that lecturers were receiving information and communication throughout the day. This made it difficult for many academics to decide when to respond or not to work-related messages and/or emails; this was true for many of the participants in this study during the Covid-19 pandemic.

Although not all academics were negatively affected by the blurring of work and family boundaries, the new normal came with many challenges and adjustments for most. Some of these adjustments had health, financial and relationship implications.

\section{Conclusion and Recommendations}

Although the temporal and spatial divide between work and home is not new, this study revealed the way in which Covid-19 accelerated this blurring and its impact on roles, family time, relationships and the general well-being of academics. Besides the challenges, the academics resiliently negotiated work-home spaces and made the necessary adjustment to the new normal. The boundary theory assisted in understanding the way in which lecturers experienced the blurring of boundaries between work and home and the consequences of blurring work-home interfaces.

This study recommends that Unisa management clearly communicate and actively manage expectations related to the workload of academics during pandemics. The university needs to adequately empower and support academics to manage their workloads during this time by making available all relevant resources for effective online education delivery. In conclusion, the real extent of the impact of Covid-19 on academics may take time to measure or realise, but it will help if employer-employee relationships are properly nurtured during crises, such as the Covid-19 pandemic, as these relationships have an impact on academics' productivity and well-being.

\section{Acknowledgements}

The authors would like to thank the Department of Curriculum and Instructional Studies in the College of Education at Unisa for funding, the Open Distance Learning Research Unit at Unisa for providing comments on our first draft, and the editor and peer reviewers for their insightful and thoughtful comments. 


\section{References}

Ashforth, Blake E., E. Glen Kreiner, and Mel Fugate. 2000. “All in a Day’s Work: Boundaries and Micro Role Transitions.” Academy of Management Review 25 (3): 472-91. https://doi.org/10.5465/amr.2000.3363315.

Baijnath, Narend. 2014. "Curricular Innovation and Digitisation at a Mega University in the Developing World - The UNISA ‘Signature Course' Project.” Journal of Learning for Development 1 (1)

Brady, A. K., and D. Pradhan. 2020. "Learning without Borders: Asynchronous and Distance Learning in the Age of COVID-19 and Beyond." ATS Scholar 1 (3): 233-42. https://doi.org/10.34197/ats-scholar.2020-0046PS.

Braun, Virginia, and Victoria Clarke. 2012. "Thematic Analysis.” In APA Handbook of Research Methods in Psychology, Vol 2: Research Designs: Quantitative, Qualitative, Neuropsychological, and Biological, edited by Cooper Harris, Paul M. Camic, Debra L. Long, A. T. Panter, David Rindskopf, and Kenneth J. Sher, 57-71. https://psycnet.apa.org/doi/10.1037/13620-004.

Brown, Wiley Steven. 2016. Toward an Understanding of the Impact of Mobile Data Services on Individual Quality of Life. Greensboro: University of North Carolina.

Clark, Sue Campbell. 2000. "Work/Family Border Theory: A New Theory of Work/Family Balance.” Human Relations 53 (6): 747-70. https://doi.org/10.1177/0018726700536001.

Craig, Lyn. 2020. "Coronavirus, Domestic Labour and Care: Gendered Roles Locked Down.” Journal of Sociology 56 (4): 684-92. https://doi.org/10.1177/1440783320942413.

Daniel, John. 2020. "Education and the COVID-19 Pandemic." Prospects 49 (1): 91-96. https://doi.org/10.1007/s11125-020-09464-3.

Derks, Daantje, and Arnold B. Bakker. 2014. "Smartphone Use, Work-Home Interference, and Burnout: A Diary Study on the Role of Recovery." Applied Psychology 63 (3): 411-40. https://doi.org/10.1111/j.1464-0597.2012.00530.x.

Derks, Daantje, Desiree van Duin, Maria Tims, and Arnold B. Bakker. 2015. "Smartphone Use and Work-Home Interference: The Moderating Role of Social Norms and Employee Work Engagement.” Journal of Occupational and Organizational Psychology 88 (1): 155-77. https://doi.org/10.1111/joop.12083.

Deslandes, Suely, and Tiago Coutinho. 2020. "Social Research in Digital Environments in COVID-19 Times: Theoretical and Methodological Notes." Cadernos de Saúde Pública 36. https://doi.org/10.1590/0102-311x00223120.

Dhawan, Shivangi. 2020. "Online Learning: A Panacea in the Time of COVID-19 Crisis." Journal of Educational Technology Systems 49 (1): 5-22.

https://doi.org/10.1177/0047239520934018. 
Etikan, Ilker, Sulaiman Abubakar Musa, and Rukayya Sunusi Alkassim. 2016. "Comparison of Convenience Sampling and Purposive Sampling." American Journal of Theoretical and Applied Statistics 5 (1): 1-4. https://doi.org/10.11648/j.ajtas.20160501.11.

Etzion, D., D. Eden, and Y. Lapidot. 1998. "Relief from Job Stressors and Burnout: Reserve Service as a Respite.” Journal of Applied Psychology 83 (4): 577-585. https://doi.org/10.1037/0021-9010.83.4.577.

Field, Justin Craig, and Xi Wen Chan. 2018. "Contemporary Knowledge Workers and the Boundaryless Work-Life Interface: Implications for the Human Resource Management of the Knowledge Workforce." Frontiers in Psychology 9. https://doi.org/10.3389/fpsyg.2018.02414.

Gurukkal, Rajan. 2020. "Will COVID-19 Turn Higher Education into Another Mode?” 89-96. https://doi.org/10.1177/2347631120931606.

Hamilton, Jill B. 2020. "Rigor in Qualitative Methods: An Evaluation of Strategies among Underrepresented Rural Communities.” Qualitative Health Research 30 (2): 196-204. https://doi.org/10.1177/1049732319860267.

Hodges, Charles, Stephanie Moore, Barb Lockee, Torrey Trust, and Aaron Bond. 2020. “The Difference between Emergency Remote Teaching and Online Learning." Educause Review 27 (1): 1-9.

Iyamu, T. 2018. "Collecting Qualitative Data for Information Systems Studies: The Reality in Practice." Education and Information Technologies 23 (5): 2249-64.

Khan, Nada, Daniel Jones, Adam Grice, Sarah Alderson, Stephen Bradley, Paul Carder, Jessica Drinkwater et al. 2020. “A Brave New World: The New Normal for General Practice after the COVID-19 Pandemic.” BJGP open 4 (3). https://doi.org/10.3399/bjgpopen20X101103.

Kinman, Gail. 2016. "Managing the Work-Home Interface: The Experience of Women Academics." In Exploring Resources, Life-Balance and Well-Being of Women who Work in a Global Context, edited by R. Gervais and P. Milear, 127-144. Cham: Springer. https://doi.org/10.1007/978-3-319-31736-6_8.

Köffer, Sebastian, Lea Anlauf, Kevin Ortbach, and Björn Niehaves. 2015. “The Intensified Blurring of Boundaries between Work and Private Life through IT Consumerisation."

Kreiner, Glen E., Elaine C. Hollensbe, and Mathew L. Sheep. 2009. "Balancing Borders and Bridges: Negotiating the Work-Home Interface via Boundary Work Tactics." Academy of Management Journal 52 (4): 704-30. https://doi.org/10.5465/amj.2009.43669916.

Kylin, Camilla. 2007. "Coping with Boundaries - A Study on the Interaction between Work and Non-Work Life in Home-Based Telework." PhD dissertation, Psykologiska Institutionen. 
Lorelli, Nowell S., Jill M. Norris, Deborah E. White, and Nancy J. Moules. 2017. "Thematic Analysis: Striving to Meet the Trustworthiness Criteria." International Journal of Qualitative Methods. https://doi.org/10.1177/1609406917733847.

Manzanedo, Rubén D., and Peter Manning. 2020. "COVID-19: Lessons for the Climate Change Emergency." Science of the Total Environment 742: 140563. https://doi.org/10.1016/j.scitotenv.2020.140563.

Mellner, Christin. 2016. “After-Hours Availability Expectations, Work-Related Smartphone Use during Leisure, and Psychological Detachment: The Moderating Role of Boundary Control." International Journal of Workplace Health Management. https://doi.org/10.1108/IJWHM-07-2015-0050.

Moore, Michael Grahame. 2013. "The Theory of Transactional Distance.” In Handbook of Distance Education, 84-103. Routledge.

Nippert-Eng, C. E. 1996. Home and Work. Chicago: University of Chicago Press. https://doi.org/10.7208/chicago/9780226581477.001.0001.

Ogundokun, Roseline O., Adewale F. Lukman, Golam B. M. Kibria, Joseph B. Awotunde, and Benedita B. Aladeitan. 2020. "Predictive Modelling of COVID-19 Confirmed Cases in Nigeria.” Infectious Disease Modelling 5: 543-8.

Park, Y., C. Fritz, and S. M. Jex. 2011. "Relationships between Work-Home Segmentation and Psychological Detachment from Work: The Role of Communication Technology Use at Home.” Journal of Occupational Health Psychology 16 (4): 457. https://doi.org/10.1037/a0023594.

Ruppanner, Leah, and Matt L. Huffman. 2014. "Blurred Boundaries: Gender and Work-Family Interference in Cross-National Context." Work and Occupations 41 (2): 210-36. https://doi.org/10.1177/0730888413500679.

Saldaña, Johnny. 2021. The Coding Manual for Qualitative Researchers. Sage.

Stadtlander, Lee, Amy Sickel, Lori LaCivita, and Martha Giles. 2017. "Home as Workplace: A Qualitative Case Study of Online Faculty Using Photovoice.” Journal of Educational Research and Practice 7 (1). https://doi.org/10.5590/JERAP.2017.07.1.04.

Suen, Lee-Jen Wu, Hui-Man Huang, and Hao-Hsien Lee. 2014. “A Comparison of Convenience Sampling and Purposive Sampling." Hu Li Za Zhi 61 (3): 105-11. https://doi.org/10.6224/jn.61.3.105.

Tabane, R. 2020. College Assembly Wellness Item. University of South Africa.

Tait, A. W. 2013. "Editorial.” Journal of Learning for Development 1 (1). http://j14d.org/index.php/ej14d/article/view/39/20. 
Ten Brummelhuis, Lieke L., and Arnold B. Bakker. 2012. “A Resource Perspective on the Work-Home Interface: The Work-Home Resources Model.” American Psychologist 67 (7): 545. https://doi.org/10.1037/a0027974.

Van Hooff, Madelon L. M., Sabine A. E. Geurts, Michiel A. J. Kompier, and Toon W. Taris. 2006. "Work-Home Interference: How does it Manifest itself from Day to Day?" Work and Stress 20 (2): 145-62. https://doi.org/10.1080/02678370600915940.

Yin, Robert K. 2009. "How to Do Better Case Studies." The SAGE Handbook of Applied Social Research Methods 2: 254-82.

Zawacki-Richter, Olaf. 2021. "The Current State and Impact of Covid-19 on Digital Higher Education in Germany." Human Behavior and Emerging Technologies 3 (1): 218-26. https://doi.org/10.1002/hbe2.238. 